\title{
Tailoring the optical properties of poly(3- hexylthiophene) by emulsion processing using polymeric macrosurfactants
}

\author{
F.D. Fleischli ${ }^{\mathrm{a}, \mathrm{b}}, *$ N. Ghasdian ${ }^{\mathrm{c}}$, T.K. Georgiou ${ }^{\mathrm{a}}$ and N. Stingelin ${ }^{\mathrm{a}, \mathrm{b}}$ \\ Here we demonstrate that the use of macrosurfactants in the production of poly(3- \\ hexylthiophene) (P3HT):water dispersion allows to drastically change the semiconductor's \\ molecular aggregation, leading to pronounced $\mathrm{H}$ - or J-like behaviour depending on the \\ macrosurfactant used and the conditions selected to produce the dispersions. No correlation \\ with the particle size and optical response is found, indicating that it is the pre-assembly in the \\ initial emulsion and possibly additional features such as the thermoresponsiveness of one of \\ the macrosurfactants that lead to the specific molecular arrangement of the P3HT. Considering \\ the broad variety of macrosurfactants that can be synthesised based already on the building \\ blocks (co-polymer units) used here, it is clear that this approach can widen the tool box \\ towards structural control of organic semiconductors, and macromolecular materials \\ especially.
}

\section{Introduction}

In recent years, there has been increasing interest in organic semiconductors, as these materials allow fabrication of discrete thin-film field-effect transistors (FETs), light-emitting diodes (LEDs), photovoltaic cells (OPVs), sensors, or integrated structures such as radio-frequency identification tags, ${ }^{1-8}$ to name a few applications. These optoelectronic devices consist of a variety of different materials, each of them chosen due to its specific properties. However, often, the processing steps (including solvent and/or temperature treatments) necessary to reach the best performance of one material, derogate the properties of another component. This is especially true for the semiconductors forming the active layer. They are highly sensitive to changes in the selection of processing conditions because these can drastically affect their molecular order and packing on all length scale and, hence, their macroscopic properties. $^{1,9-17}$

Emulsions and dispersions can offer an alternative approach towards (self-)assembling — as well as patterning — of multifunctional systems including organic semiconductors. The reason is that particles of different size, consisting of different materials and/or with pre-defined properties can be realised using this approach, and the constituting components may be directed to adopt the desired structure and molecular arrangement prior to the final device fabrication.
In the 'plastic electronics' area, previous studies have demonstrated that particles consisting of conjugated polymers can be successfully made via emulsion routes; however it seems that the full potential of this approach has not yet been fully exploited. For instance, most often, the commercially available surfactant sodium dodecylsulphate (SDS) was employed to produce organic semiconducting dispersions and nanoparticles, ${ }^{18-22}$ while many other systems have remained uninvestigated. We therefore aim here at expanding the library of surfactants used in combination with organic semiconducting matter and explore utilisation of polymeric macrosurfactants with the goal to realise emulsions comprising tunable semiconductor structures, with focus on manipulating the optical characteristics of the active material(s).

We selected polymeric macrosurfactants, which generally are based on amphiphilic block copolymers, as 'emulsifiers' because they offer advantages compared to the traditional small molecular weight surfactants. Specifically, with a smaller quantity they are able to stabilise emulsions or dispersion, ${ }^{23,24}$ promising therefore to only have a minor impact (if any) on the optoelectronic properties of the semiconducting material(s) that is (are) being 'encapsulated'. Moreover, polymer macrosurfactants are usually easier to manipulate and to tailor compared to traditional surfactants, thus, often lead to a better stability of the emulsions. ${ }^{23,25-28}$ 
Two polymeric macrosurfactants were chosen that are based on block copolymers with the same hydrophobic block, $n$-butyl methacrylate (BuMA), and different hydrophilic moieties (poly(ethylene glycol) methyl methacrylate (PEGMA) and 2(dimethylamino)ethyl methacrylate (DMAEMA)). Specifically, we selected $\mathrm{BuMA}_{59}-b$-DMAEMA ${ }_{83}$, a macrosurfactant that is both $\mathrm{pH}$ - and thermo-responsive due to the presence of the DMAEMA groups ${ }^{29-32}$ and PEGMA $_{16}-b-\mathrm{BuMA}_{42}$, which is based on two non-ionic monomers. In an organic solvent, these macrosurfactants are expected to from inverse micelles with the hydrophobic block (BuMA) forming the shell (stretched chains) and the hydrophilic block (PEGMA or DMAEMA) coiled in the core. Schematics of the chemical structures of $\mathrm{BuMA}_{59}-b$ DMAEMA $_{83}$ and PEGMA $_{16}-b-$ BuMA $_{42}$ are shown in Fig. 1.

As the active material we choose to use poly(3-hexyl thiophene) (P3HT) as model system because it is one of the most investigated semiconducting polymer. ${ }^{33}$ Moreover, the selection of solvents (quality, evaporation kinetics), use of specific temperature treatment and/or deposition onto certain substrates (e.g., substrates that are covered with self-assembled monolayers, patterned with surface structures, or allowing confined solidification) were shown to affect the ordering and arrangement of P3HT from the molecular level to the macroscale. ${ }^{10,34-42}$ Processing can, thus, have a drastic effect on the optoelectronic features of the resulting structures and lead to significant changes in the photophysical aggregation of the P3HT molecules.

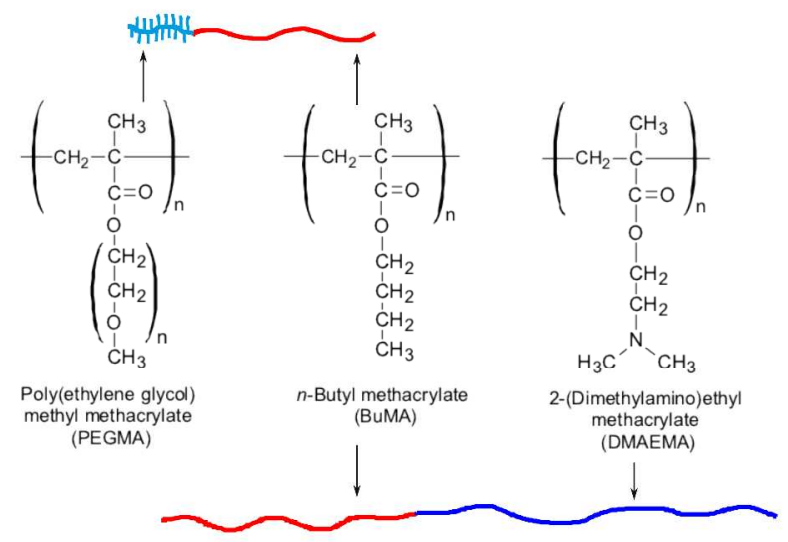

Fig. 1: Schematic illustration and chemical structures of the diblock copolymer macrosurfactants used here. The BuMA-, DMAEMAand PEGMA-blocks are coloured in red, dark blue and light blue, respectively.

The photophysical aggregation of P3HT can, according to Spano and coworkers, be explained as a result of the competition of interchain and intrachain exciton coupling that is believed to be highly sensitive to the short- and, possibly, longrange ordering of the $\mathrm{P} 3 \mathrm{HT}$ molecules. ${ }^{43,44} \mathrm{H}$-aggregate like behaviour results from a dominant interchain coupling and leads, amongst other things, to a low $\mathrm{A}_{0-0}$ transition in the UV-
Vis absorption. ${ }^{43}$ If the intrachain coupling is dominant, the material shows J-aggregate-like behaviour with a pronounced $\mathrm{A}_{0-0}$ transition. Generally, P3HT structures display H-like aggregation, however, in certain scenarios, they have been found to feature J-aggregate-like behaviour: e.g., in nanofibres produced during slow solidification from a good solvent, ${ }^{42}$ or in films blended with a polar polymer such as poly(ethylene oxide) (PEO) (i.e., the long-chain derivative of the PEG moiety selected in one of our macrosurfactant). ${ }^{45}$ This should allow us to monitor changes in short- and possibly long-range order induced by the nanoparticle formation through emulsion processing, which is believed to lead to these two different aggregation states. $^{46}$

\section{Materials and Methods}

\section{Materials}

Synthesis of polymeric macrosurfactants. Two different block copolymers were used as macrosurfactants. They were synthesised as outlined below. 1-Methoxy-1(trimethylsiloxy)-2methyl propene (MTS, initiator, 99\%), sodium metal, 2,2diphenyl-1-picrylhydrazyl hydrate (DPPH, free radical inhibitor, 99\%), and (PEGMA $\left(\mathrm{M}_{\mathrm{W}}=300 \mathrm{gmol}^{-1}\right.$, monomer) were purchased from Aldrich, UK. Tetrabutylammonium hydroxide $\left(40 \%\right.$ in water), basic alumina $\left(\mathrm{Al}_{2} \mathrm{O}_{3}, 95 \%\right)$, potassium metal, DMAEMA (monomer, 99\%) and BuMA (monomer, 99\%) were purchased from Acros Organics, UK. Tetrahydrofuran (THF, polymerisation solvent, 95\%) and $n$ hexane (precipitation solvent, 95\%) were purchased from Fisher Scientific.

DMAEMA and BuMA monomers were passed twice through basic alumina to remove inhibitors and protic impurities and stirred over $\mathrm{CaH}_{2}$ for 3 hours in the presence of DPPH. Both monomers were kept refrigerated until distillation before use. PEGMA was passed twice through basic alumina as a $50 \% \mathrm{v} / \mathrm{v}$ solution in THF and stirred overnight over $\mathrm{CaH}_{2}$. No DPPH was added to the PEGMA monomer solution due to the inability to distil PEGMA prior to use. The solution was refrigerated until the polymerisation and it was filtered directly into the reaction flask with a $0.45 \mu \mathrm{m}$ syringe filter.

The initiator was distilled once before polymerisation and kept sealed under argon until use. Tetrabutylammonium bibenzoate (TBABB) was the polymerisation's catalyst and was synthesised by the reaction of tetrabutylammonium hydroxide and benzoic acid, as described by Dicker et al. ${ }^{47}$ The catalyst was dried and stored under vacuum until use. THF was refluxed over a potassium/sodium amalgam for 3 days to dry before polymerisation. All glassware was dried overnight at $140{ }^{\circ} \mathrm{C}$ and assembled hot under dynamic vacuum before use.

The synthetic procedure for the two macrosurfactants was similar. Specifically, a typical sequential group transfer polymerisation (GTP) procedure was followed for both of 
Table 1: Structure of the block copolymers and single blocks including number and weight average molecular weights, $M_{\mathrm{n}}$ and $M_{\mathrm{w}}$, respectively, and weight block fraction.

\begin{tabular}{|c|c|c|c|c|c|}
\hline \multirow{2}{*}{ Polymer structure } & \multirow{2}{*}{$\begin{array}{c}M_{\mathrm{n}} \\
\left(\mathrm{g} \mathrm{mol}^{-1}\right)\end{array}$} & \multirow{2}{*}{$\begin{array}{c}M_{\mathrm{w}} / M_{\mathrm{n}} \\
(-)\end{array}$} & \multicolumn{3}{|c|}{ Block content $(\mathrm{wt} \%)^{*}$} \\
\hline & & & PEGMA & BuMA & DMAEMA \\
\hline PEGMA $_{16}$ & 4100 & 1.11 & 1.00 & - & - \\
\hline PEGMA $_{16}-b-\mathrm{BuMA}_{42}$ & 10000 & 1.06 & 0.44 & 0.56 & - \\
\hline BuMA $_{59}$ & 7200 & 1.16 & - & 1.00 & - \\
\hline $\mathrm{BuMA}_{59}-b-\mathrm{DMAEMA}_{83}$ & 19100 & 1.12 & - & 0.39 & 0.61 \\
\hline
\end{tabular}

*Based on NMR results

them. ${ }^{25,}{ }^{29-32,48}$ The synthesis of PEGMA $_{16}-b-$ BuMA $_{42}$ is given below as an example. The polymerisation exothermal was monitored using a digital thermometer to identify whether the polymerisation was successful and when it was finished.

Freshly distilled THF (124 mL) and MTS $(0.50 \mathrm{~mL}, 0.43 \mathrm{~g}$, $2.46 \mathrm{mmol})$ were syringed into a $250 \mathrm{~mL}$ round bottom flask containing TBABB $(\sim 10 \mathrm{mg})$ previously sealed with a septum and purged with argon. Firstly a PEGMA solution in THF was added (35 $\mathrm{mL}$ of a $50 \mathrm{vol} \%$ solution, $18.5 \mathrm{~g}, 61.5 \mathrm{mmol}$ ) using a syringe and a filter. The temperature rose by $4.7^{\circ} \mathrm{C}$. After 10 minutes the exothermic reaction had abated and two $0.1 \mathrm{~mL}$ aliquots of the reaction solution were extracted for GPC and $1 \mathrm{H}$ NMR analysis. Then BuMA (13.5 mL, $12.3 \mathrm{~g}, 86.1 \mathrm{mmol})$ was added using a syringe and the temperature rose by $5.5{ }^{\circ} \mathrm{C}$. Subsequently two more $0.1 \mathrm{~mL}$ aliquots were collected for GPC and ${ }^{1} \mathrm{H}$ NMR analysis. For the $\mathrm{BuMA}_{59}-b$-DMAEMA 83 synthesis, the BuMA monomer was polymerised first and the DMAEMA monomer second. After the polymerisations were completed both macrosurfactants were recovered by precipitation through $n$-hexane and dried at room temperature in a vacuum oven for two days. Table 1 summarises the number-average molecular weights $M_{n}$, the molecular weight distribution, MWD, and compositions of the precursors to the macrosurfactants and the macrosurfactants as determined by GPC and NMR, respectively.

Micelle formation. The behaviour of macrosurfactants in a solvent provides an indication of their behaviour in an emulsion. Therefore, we dissolved both macrosurfactants (which distinguish in the type of the hydrophilic block and block length) in water, cyclohexane and chloroform, the same solvents as we used for the production of the emulsions with P3TH. Reassuringly, according to dynamic light scattering measurements, micelle/aggregate formation does occur (see Supplementary Information) for both materials in all three selected solvents, although in chloroform a high fraction of the surfactants, especially $\mathrm{PEGMA}_{16}-b$ - $\mathrm{BuMA}_{42}$, appeared to be present as single-coiled molecules, likely due to the good solubility of the co-polymer blocks in this solvent.

Dispersions of P3HT. Regioregular poly(3-hexyl thiophene) (P3HT; $M_{\mathrm{w}}=31 \mathrm{~kg} \mathrm{~mol}^{-1}$ ) was purchased from Sigma-Aldrich (batch LF430202). Chloroform and cyclohexane were purchased from Sigma-Aldrich and used without further purification.

P3HT dispersions were produced via an emulsion route. P3HT was dissolved in the organic solvent (chloroform or cyclohexane, $2 \mathrm{mg} \mathrm{mL}^{-1}$ ) forming the organic phase of the emulsion. The water phase was based on distilled water. One of the macrosurfactants $\left(20 \mathrm{mg} \mathrm{mL}^{-1}\right)$ was then dissolved either in the organic (chloroform or cyclohexane) or water phase (see Fig. 2). The water and organic phase were subsequently stirred over night before they were mixed together (see below).

Emulsions were formed by mixing the oil and water phase at a ratio of $1: 3$ by volume at either room temperature (RT) or 80 ${ }^{\circ} \mathrm{C}$. The total liquid volume was $2 \mathrm{~mL}$. For emulsification, they were homogenised ultrasonically (Hielscher UP5OH, $50 \mathrm{~W}, 30$ $\mathrm{kHz}$ ) or mechanically (Cole-Palmer LabGEN 7, $125 \mathrm{~W}$, up to $35,000 \mathrm{rpm})$ for $60 \mathrm{~s}$. Subsequently, these oil-in-water emulsions were poured into $20 \mathrm{~mL}$ of distilled water, kept at the same temperature as the emulsions, to further separate the dispersed 'oil' droplets. These diluted emulsions were then 

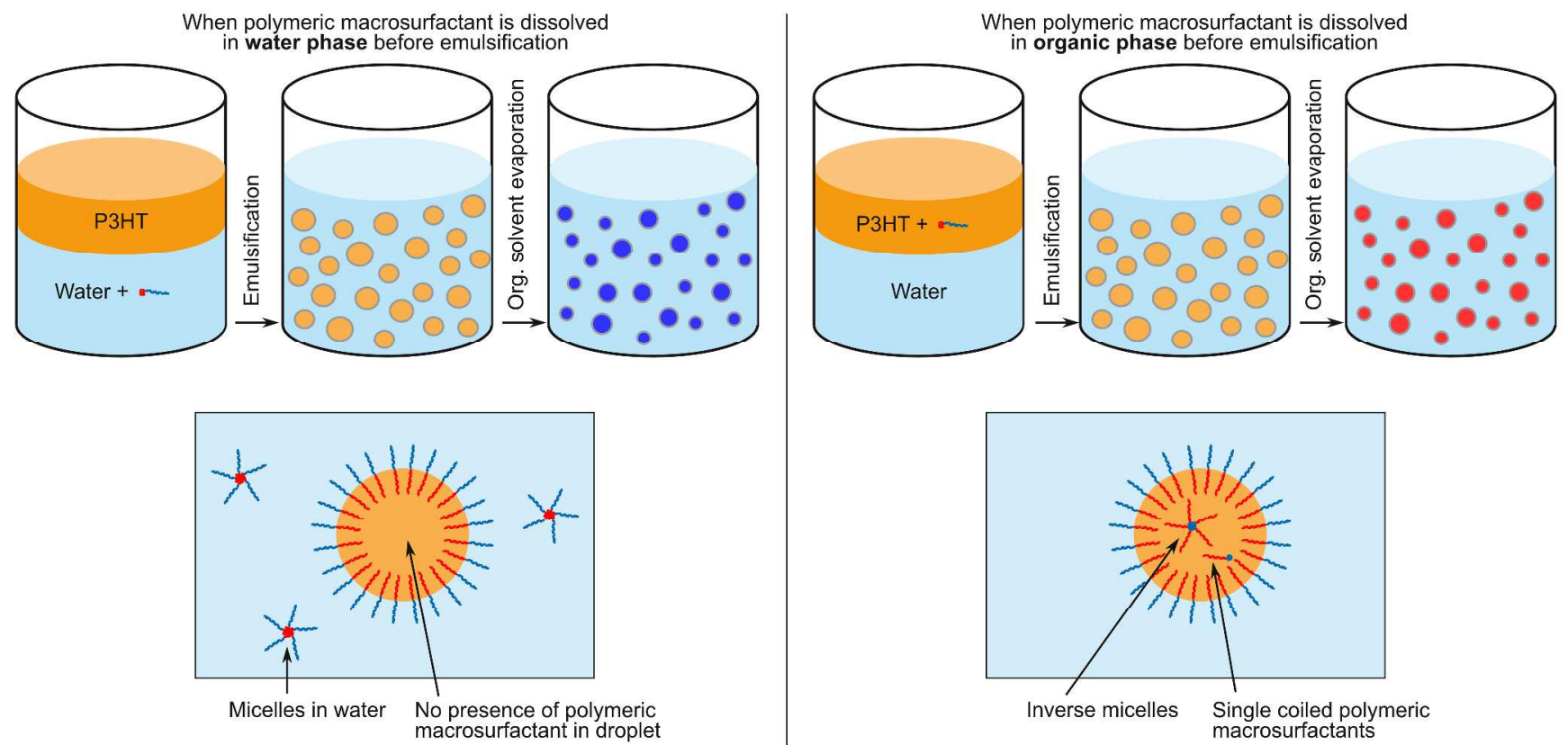

Fig. 2: Schematic illustration of the route used to produce P3HT:water dispersions. The polymeric macrosurfactant is dissolved either a) in the water or b) organic phase, respectively, before emulsification via mechanical stirring or ultrasonification. In the final step the organic solvent is removed, leading to solid P3HT particles dispersed in water.

stirred - and if processed at $80^{\circ} \mathrm{C}$ let cool down to RT - until all organic solvent evaporated, leading to the formation of P3HT particles. The resulting dispersions of P3HT particles in water could readily be stored in glass vials in the dark.

\section{Methods}

Dynamic light scattering. The average particle size in the P3HT dispersions was determined by dynamic light scattering using a ZetasizerNano $S$. For this purpose, 20 measurements were averaged; the P3HT dispersions were diluted to minimize the interaction between the particles.

UV-Vis absorption. The absorption spectra of the P3HT dispersions were recorded using a Perkin Elmer Lambda 25 $\mathrm{UV}-\mathrm{V}$ is spectrometer. If necessary, the $\mathrm{P} 3 \mathrm{HT}$ dispersions were diluted.

Gel Permeation Chromatography. The molecular weights (MWs) and the molecular weight distribution (MWDs, $M_{\mathrm{w}} / M_{\mathrm{n}}$ ) of all the linear precursors to the copolymers and all the copolymers were determined by gel permeation chromatography (GPC) using a single $P L$-Mixed " $E$ ”' Polymer
Laboratories column. THF containing 5\% triethylamine was the mobile phase and was pumped with a flow rate at $1 \mathrm{~mL}$ min-1 using a Viscotek vt7510 pump. A Viscotek 3580 differential refractometer was used to measure the refractive index signal. The calibration curve was based on nine linear and low-dispersity poly(methyl methacrylate)s (PMMAs) of a $M_{\mathrm{w}}$ of $690,5720,1020,1200,1960,4000,8000,13300$ and $20010 \mathrm{~g} \mathrm{~mol}^{-1}$.

Proton Nuclear Magnetic Resonance Spectroscopy ( ${ }^{1}$ H-NMR). A JEOL $400 \mathrm{MHz}$ spectrometer instrument was used to acquire the proton NMR spectra of the copolymers and their precursors in $\mathrm{CDCl}_{3}$.

\section{Results and Discussion}

In order to probe an as broad parameter space as possible, we prepared emulsions with both selected macrosurfactants and varied i) the organic solvent in the oil phase (i.e. chloroform or cyclohexane), ii) the phase in which the macrosurfactant was dissolved (i.e. water or organic phase (see Fig. 2)), iii) the temperature at which the emulsion was produced (i.e. the temperature at which the water and organic phase were mixed), 
and iv) the homogenisation technique (mechanically vs. ultrasonically). All routes let to stable dispersions of $\mathrm{P} 3 \mathrm{HT}$ particles in water, allowing after evaporation of the organic solvent straight-forward measurements of the respective UV-Vis absorption spectra.

Intriguingly, for systems using $\mathrm{PEGMA}_{16}-b-\mathrm{BuMA}_{42}$ as macrosurfactant, large variations in the optical response can already be observed when the solvent used for the preparation of the oil phase was varied (see Fig. 3b). Indeed, comparing dispersion where the 'oil' and water phase were mixed at $80^{\circ} \mathrm{C}$ and then were homogenised ultrasonically, we find large differences in the $\mathrm{A}_{0 / 0}$ absorption transition depending whether chloroform or cyclohexane was used in the organic phase indication of the promise of this strategy to manipulate the P3HT arrangement and order at small length scale. More specifically, using chloroform for dissolving P3HT leads in combination with this surfactant to a high $\mathrm{A}_{0 / 0}$ transition, i.e. a strong J-like character $\left(\mathrm{A}_{0 / 0} / \mathrm{A}_{0 / 1} \approx 0.98\right)$, especially when the dispersions were prepared from an emulsion where the macrosurfactant was dissolved in the water phase (see Fig. 3b). In contrast, with cyclohexane as the solvent for the organic phase, dispersions with the optical behaviour typical for H-like P3HT aggregates were obtained with PEGMA $_{16}-b-B_{4 M A}$, again with a somewhat higher $\mathrm{A}_{0 / 0}$ absorption transition when they were processed with the macrosurfactant dissolved in the water phase.

Somewhat surprisingly, no drastic differences were observed in the UV-vis spectra of the P3HT dispersions when the other macrosurfactant, i.e. $\mathrm{BuMA}_{59}-b$-DMAEMA ${ }_{83}$ was used (see Fig. 3a). We therefore went on and investigated whether we can induce J-like aggregation in these systems by changing the method of stirring of the emulsions as well as the emulsion temperature while stirring $\left(80^{\circ} \mathrm{C}\right.$ vs. RT). We used for this purpose dispersion with cyclohexane as the solvent for the organic phase and dissolved the macrosurfactant in water because under these conditions, we have observed rather H-like aggregation in our first set of experiments. For comparison, we prepared additional emulsions with PEGMA $_{16}-b$-BuMA 42 employing the same parameters.

A few striking observations can be made (see Fig. 3c,d): i) Using mechanical homogenisation of the emulsions at $80{ }^{\circ} \mathrm{C}$, we can change the generally $\mathrm{H}$-like absorption of dispersions, which were produced with BuMA $_{59}-b$-DMAEMA ${ }_{83}$ dissolved in the water phase, to J-like-aggregate behaviour with a very pronounced $\mathrm{A}_{0 / 0}$ absorption transition. ii) Similarly, for systems prepared with the other surfactant, PEGMA $_{16}-b-\mathrm{BuMA}_{42}$, (P3HT dissolved in cyclohexane as organic phase; PEGMA ${ }_{16}^{-}$ $b$-BuMA 42 dissolved in water), when mechanically homogenised, a significantly higher $\mathrm{A}_{0 / 0} / \mathrm{A}_{0 / 1} \approx 0.94$ is obtained compared to dispersions of identically composition but mixed ultrasonically; that is a high $\mathrm{A}_{0 / 0}$ transition, characteristic for $\mathrm{J}$ like aggregates, is induced that is approaching the one found in dispersions made from a chloroform-based organic phase.

The above shows that following an emulsion route, we apparently gain the capability to manipulate the molecular ordering of P3HT and, hence, their photophysical properties such as H- vs. J- aggregation. The question remains what leads to the change in optical behaviour of the various P3HT-in-water dispersions. One factor could be the particle size. DLS data collected on the various systems are displayed in Fig. 4. We find that for $\mathrm{BuMA}_{59}-b$-DMAEMA ${ }_{83}$-based systems, the particle size does not drastically vary and in average is around 300 to $400 \mathrm{~nm}$, although some particles in the 60 to $80 \mathrm{~nm}$ - range are present in dispersions prepared with cyclohexane as solvent for the oil phase, the macrosurfactant having been dissolved in water, and the emulsion having been mechanically stirred at $80{ }^{\circ} \mathrm{C}$. The observed discrepancy in the $\mathrm{A}_{0 / 0}$ absorption transition in the dispersions produced with this macrosurfactant may, thus, likely origin from other effects, e.g., its thermo-responsiveness. In contrast, for the dispersions fabricated with PEGMA $_{16}-b$-BuMA 42 noticeably different particle sizes are measured, with sizes ranging from $100 \mathrm{~nm}$ to more than $1 \mu \mathrm{m}$. In addition, bi-modal or even more complex size distributions are observed. Yet, again, no obvious correlation with particle size can be deduced, although the most J-like-aggregate behaviour is found for dispersion comprising particles of a relatively monodisperse particle size distribution around $200 \mathrm{~nm}$.
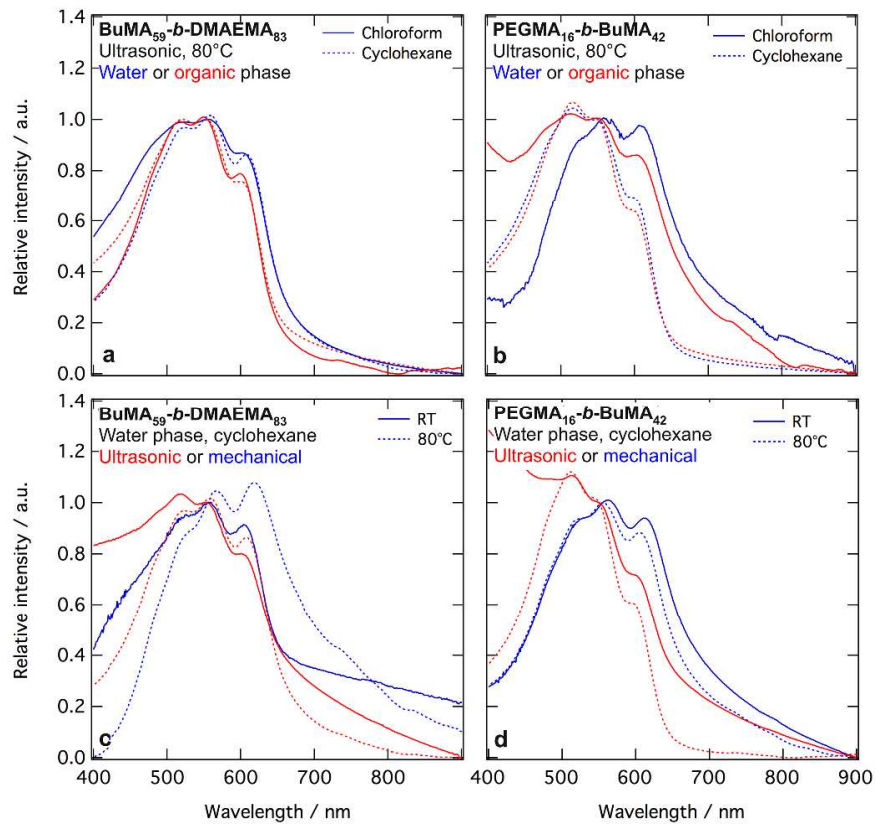

Fig. 3: UV-Vis absorption spectra of P3HT dispersions made with a)

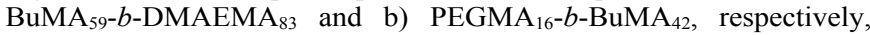
whereby the macrosurfactant was dissolved in the water- (blue) or oil phase (red), chloroform (solid line) or cyclohexane (dotted line) was used as the solvent for P3HT. UV-Vis absorption spectra of P3HT dispersions made with c) $\mathrm{BuMA}_{59}-b$-DMAEMA $\mathrm{D}_{83}$ and d) $\mathrm{PEGMA}_{16}-b$ BuMA $_{42}$, respectively. These emulsions were homogenised ultrasonically (red) or mechanically (blue) at RT (solid line) or $80^{\circ} \mathrm{C}$ (dotted line). Thereby, the macrosurfactant was dissolved in the water phase and cyclohexane was used to dissolve P3HT.

\section{Conclusions}

We have demonstrated that use of macrosurfactants open new opportunities in the assembly of P3HT in solution prior to device fabrication. Changes in the emulsion production, including selection of macrosurfactant, method used to homogenise the initial emulsion, the choice of emulsion temperature, etc., have a significant effect on the photophysical aggregation of the $\mathrm{P} 3 \mathrm{HT}$ macromolecules, from pronounced $\mathrm{H}$ like to J-like character, as deduced from UV-Vis spectroscopy. No direct correlation with particle size and aggregation behaviour could be made indicating that there are other 
important parameters that influence the assembly of the P3HT macromolecules in such dispersions, which requires more detailed investigations. Nonetheless, it is clear that the wide variety of macrosurfactants available and the ease to modify them, will open entirely new pathways for the assembly of organic semiconducting structures and, in particular, polymeric semiconductors.
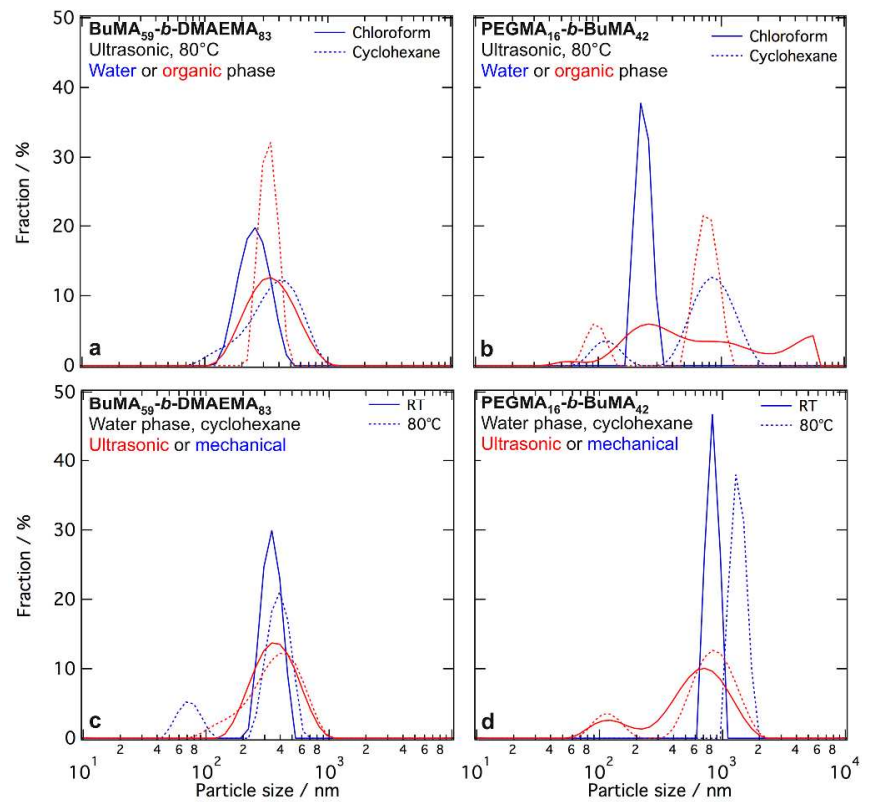

Fig. 4: Size distribution of P3HT particles in dispersions made with a) BuMA $_{59}-b$-DMAEMA ${ }_{83}$ and b) PEGMA $_{16}-b$-BuMA 42 , respectively, where the macrosurfactant was dissolved in the water- (blue) or oil phase (red) and chloroform (solid line) or cyclohexane (dotted line) was used to dissolve the P3HT. Size distribution of P3HT particles in dispersions made with c) $\mathrm{BuMA}_{59}-b$-DMAEMA 83 and d) PEGMA $_{16}-b-$ BuMA $_{42}$, respectively, whereby the emulsions were homogenised ultrasonically (red) or mechanically (blue) at RT (solid line) or $80^{\circ} \mathrm{C}$ (dotted line), with the macrosurfactant being dissolved in the water phase and cyclohexane as solvent for P3HT.

\section{Acknowledgements}

We thank the Swiss National Science Foundation for the Fellowship for prospective researchers (for F.D.F) and the University of Hull for providing Ph.D. Studentship funding (for N.G.) and Funds for Women Graduates for additional financial support. N.S. in addition is supported by a European Research Council (ERC) Starting Independent Research Fellowship under the grant agreement no. 279587

\section{Notes and references}

${ }^{a}$ Department of Materials, Imperial College London, London - UK

${ }^{b}$ Centre of Plastic Electronics, Imperial College London, London - UK

${ }^{c}$ Department of Chemistry, University of Hull, Hull - UK

1 H. Sirringhaus, Adv. Mater., 2014, 26, 1319-1335.

2 H. Sasabe and J. Kido, Eur. J. Org. Chem.,2013, 34, 7653-7663.

3 C. Murawski, K. Leo and M.C. Gather, Adv. Mater., 2013, 25, 68016827.
4 L. Dou, J. You, Z. Hong, Z. Xu, G. Li, R.A. Street and Y. Yang, Ad.v Mater., 2013, 25, 6642-6671.

5 B.K. An, R. Mulherin, B. Langley, P. Burn and P. Meredith, Org. Electron., 2009, 10, 1356-1363.

6 L. Torsi, M. Magliulo, K. Manoli and G. Palazzo, Chem Soc Rev., 2013, 42, 8612-8628.

7 B. Crone, A. Dodabalapur, Y. Y. Lin, R. W. Filas, Z. Bao, A. La Duca, R. Sarpeshkar, H. E. Katz and W. Li, Nature, 2000, 403, 521-523.

8 S. Jacob, S. Abdinia, M. Benwadih, J. Bablet, I. Chartier, R. Gwoziecki, E. Cantatore, A.H.M. van Roermund, L. Maddiona, F. Tramontana, G. Maiellaro, L. Mariucci, M. Rapisarda, G. Plmisano and R. Coppard, Solid-State Electronics, 2013, 84, $167-$ 178.

9 A. Salleo, R.J. Kline, D.M. DeLongchamp and M.L. Chabinyc, Adv. Mater., 2010, 22, 3812-3838.

10 O.G. Reid, J.A. Nekuda Malik, G. Latini, S. Dayal, N. Kopidakis, C. Silva, N. Stingelin and G. Rumbles, J. Polym. Sci. Part B: Polym Phys., 2012, 50, 27-37.

11 I. McCulloch, M. Heeney, M.L. Chabinyc, D. DeLongchamp, R.J. Kline, M. Coelle, W. Duffy, D. Fischer, D. Gundlachm B. Hamadani, R. Hamilton, L. Richter, A. Salleo, M. Shkunov, D. Sporrowe, S. Tierney and W. Zhong, Adv. Mater., 2009, 21, 10911109.

12 A.A. Virkar, S. Mannsfeld, Z. Bao and N. Stingelin, Adv. Mater., 2010, 22, 3857-3875.

13 M. Brinkmann, J PolymSci B, 2011, 49, 1218-1233.

14 H. Li, G. Giri, J.B.H. Tok and Z. Bao, MRS Bulletin, 2014, 38, 3442.

15 R. Noriega, J. Rivnay, K. Vandeval, F.P.V. Koch, N. Stingelin, P. Smith, M.F. Toney, A. Salleo, Nature Materials, 2013, 12, 1038

16 N. Shin, L.J. Richter, A.A. Herzing, J.R. Kline, D.M. DeLongchamp, Adv. Energy Materials, 2013, 3, 938-948.

17 W. Ma, J.R. Tumbleston, L. Ye, C. Wang, J. Hou, H. Ade, Adv. Materials, 2014, 26, 4234-4241.

18 D. Darwis, D. Elkington, S. Ulum, A. Stapleton, G. Bryant, X. Zhou, W. Belcher and P. Dastoor, AIP Conf. Proc., 2011, 1415, 124-127.

19 T. Kietzke, D. Neher, K. Landfester, R. Montenegro, R. Guentner and U. Scherf, Nature Materials, 2003, 2, 408-412.

20 G. Nagarjuna, M. Baghgar, J.A. Labastide, D.D. Algaier, M.D. Barnes, D. Venkataraman, ACS Nano, 2012, 6, 10750-10758.

21 A. Stapleton, B. Vaughan, B. Xue, E. Sesa, K. Burke, X. Zhou, G. Bryant, O. Werzer, A. Nelson, A.L.D. Kilcoyne, L. Thomsen, E. Wanless, W. Belcher and P. Dastoor, Solar Energy Materials and Solar Cells, 2012, 102, 114-124.

22 J.J. Richards, K.M. Weigandt and D.C. Pozzo, J. Colloids Interf. Sci., 2011, 364, 341-350.

23 S. Garnier and A. Laschewsky, Langmuir, 2006, 22, 4044-4053.

24 S.C. Hadjiyannakou, M. Vamvakaki, and C.S. Patrickios, Polymer, 2004, 45, 3681-3692.

25 N.H. Raduan, T.S. Horozov and T.K. Georgiou, Soft Matter, 2010, 6, 2321-2329.

26 S. Liu and S.P. Armes, Curr. Opin. Colloid Interface Sci., 2001, 6, 249-256.

27 T. Tadros, Adv. Colloid Interface Sci., 2009, 147-148, 281-299. 
28 A.T. Nikova, V.D. Gordon, G. Cristobal, M.R. Talingting, D.C. Bell, C. Evans, M. Joanicot, J.A. Zasadzinski and D.A. Weitz, Macromolecules, 2004, 37, 2215-2218.

29 M. A. Ward and T. K. Georgiou, J. Polym. Sci., Part A: Polym. Chem., 2010, 48, 775-783.

30 M. A. Ward and T. K. Georgiou, Soft Matter, 2012, 8, 2737-2745.

31 M. A. Ward and T. K. Georgiou, J. Polym. Sci., Part A: Polym. Chem., 2013, 51, 2850-2859.

32 M. A. Ward and T. K. Georgiou, Polym. Chem., 2013, 4, 18931902.

33 B. DeBoer, A. Facchetti, Polymer Reviews, 2008, 48, 423-431.

34 A.R. Aiyar, J.I. Hong, R. Nambiar, D.M. Collard and E. Reichmanis, Adv. Funct. Mater., 2011, 21, 2652-2659.

35 J.F. Chang, J. Clark, N. Zhao, H. Sirringhaus, D.W. Breiby, J.W. Andreasen, M.M. Nielsen, M. Giles, M. Heeney and I. McCulloch, Phys. Rev. B, 2006, 74, 115318.

36 F.S.U. Fischer, K. Tremel, M. Sommer, E.J.C. Crossland and S. Ludwigs, Nanoscale, 2012, 4, 2138-2144.

37 R.J. Kline, M.D. McGehee, E.N. Kadnikova, J. Liu, J.M.J. Frechet and M.F. Toney, Macromolecules, 2005, 38, 3312-3319.

38 B. OConnor, R.J. Kline, B.R. Conrad, L.J. Richter, D. Gundlach, M.F. Toney and D.M. DeLongchamp, Adv. Funct. Mater., 2011, 21, 3697-705

39 B. Park, A. Aiyar, M.S. Park, M. Srinivasarao and E. Reichmanis, J. Phys. Chem. C, 2011, 115, 11719-11726.

40 W. Porzio, G. Scavia, L. Barba, G. Arrighetti and S. Milita, Europ. Polym. J., 2011, 47, 273-283.

41 C. Scharsich, R.H. Lohwasser, M. Sommer, U. Asawapirom, U. Scherf, M. Thelakkat, D. Neher and A. Koehler, J. Polym. Sc. B, 2012, 50, 442-453.

42 T.P. Martin, A.J. Wise, E. Busby, J. Gao, J.D. Roehling, M.J. Ford, D.S. Larsen, A.J. Moule and J.K. Grey, J Phys Chem B, 2013, 117, 4478-4487.

43 F.C. Spano and C. Silva, Annu. Rev. Phys. Chem., 2014, 65, $477-$ 500.

44 H. Yamagata and F.C. Spano, J. Chem. Phys., 2012, 136, 184901.

45 C. Hellmann, F. Paquin, N.D. Treat, A. Bruno, L.X. Reynolds, S.A. Haque, P.N. Stavrinou, C. Silva and N. Stingelin, $A d v$ Mater., 2013, 25, 4906-4911.

46 E.T. Niles, J.D. Roehling, H. Yamagata, A.J. Wise, F.C. Spano, A.J. Moule, J.K. Grey, J. Phys. Chem. Lett., 2012, 3, 259-263.

47 I. B. Dicker, G. M. Cohen, W. B. Farnham, W. R. Hertler, E. D. Laganis and D. Y. Sogah, Macromolecules, 1990, 23, 4034-4041.

48 D. M. A. Buzza, P. D. I. Fletcher, T. K. Georgiou and N. Ghasdian, Langmuir, 2013, 29, 14804-14814. 


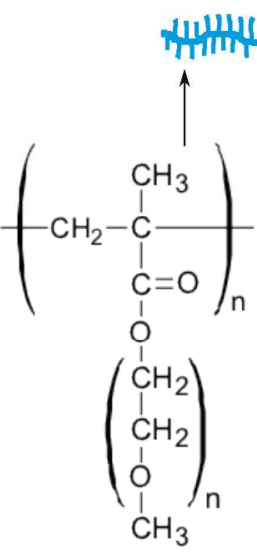

Poly(ethylene glycol) methyl methacrylate (PEGMA)

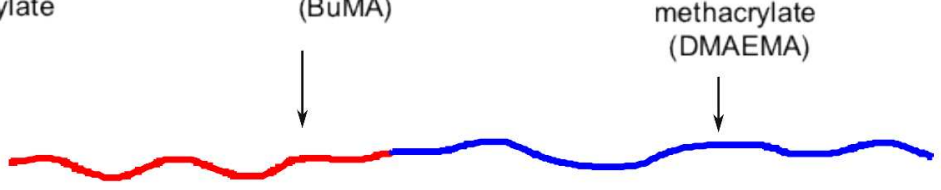

Schematic illustration and chemical structures of the diblock copolymer macrosurfactants used here. The BuMA-, DMAEMA- and PEGMA-blocks are coloured in red, dark blue and light blue, respectively. 

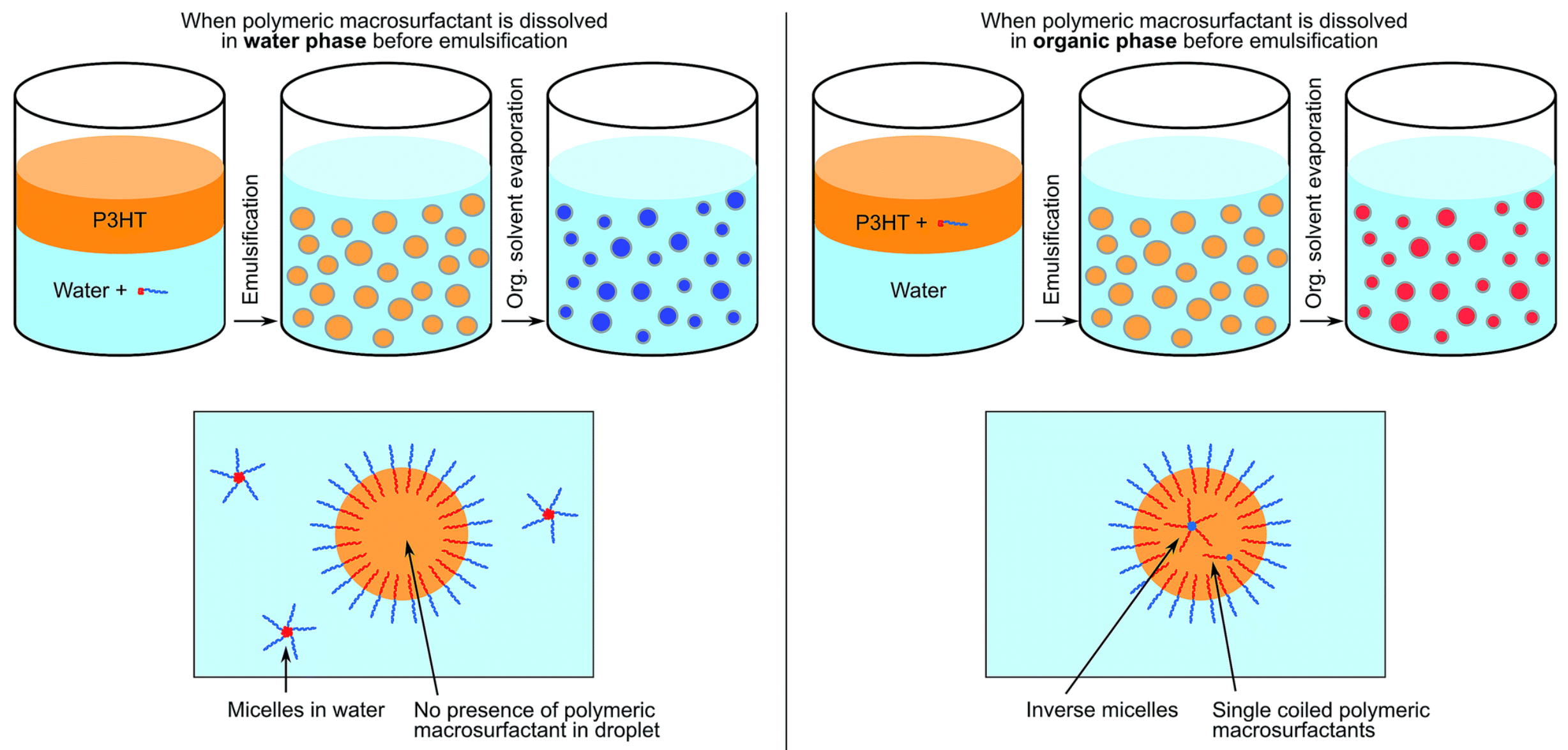

Fig. 2 Schematic illustration of the route used to produce P3HT:water dispersions. The polymeric macrosurfactant is dissolved either (a) in the water or (b) organic phase, respectively, before emulsification via mechanical stirring or ultrasonification. In the final step the organic solvent is removed, leading to solid P3HT particles dispersed in water. 

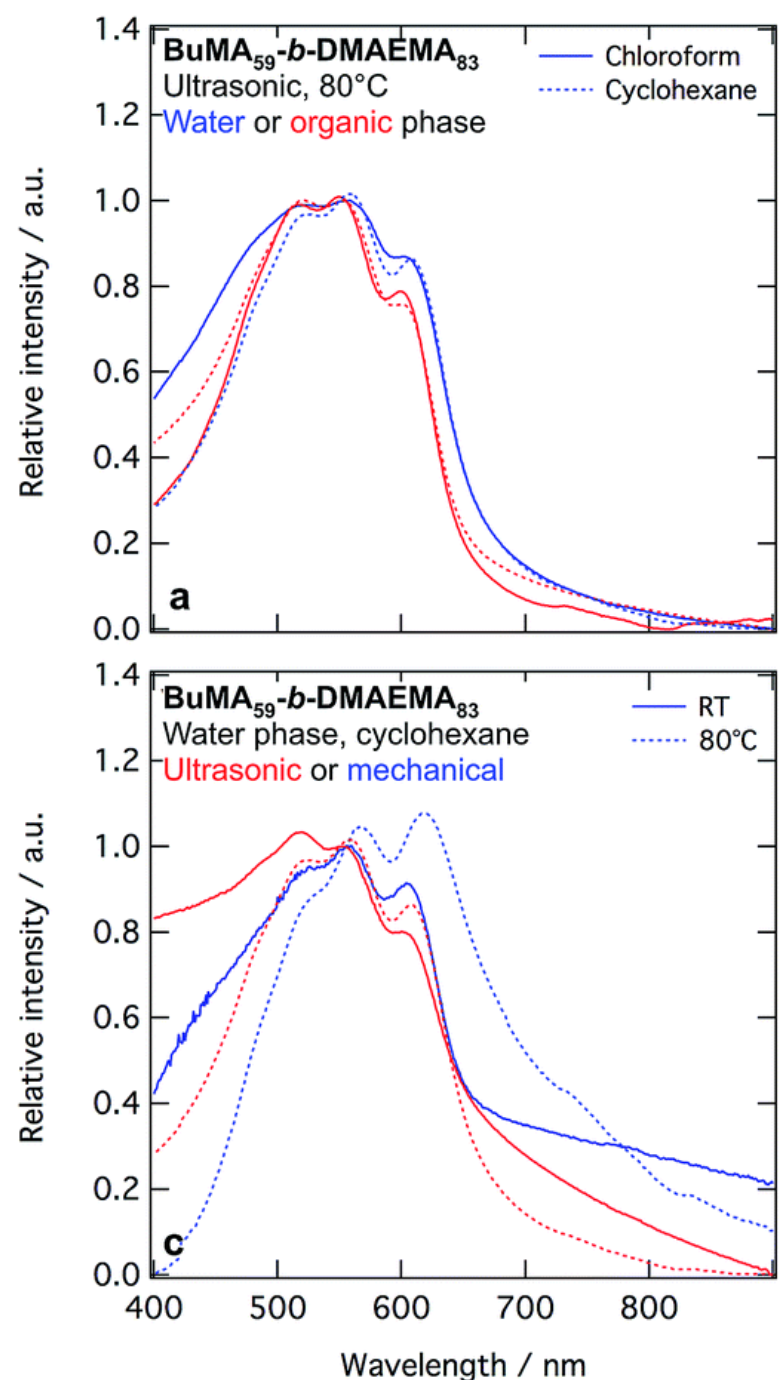

Wavelength / nm
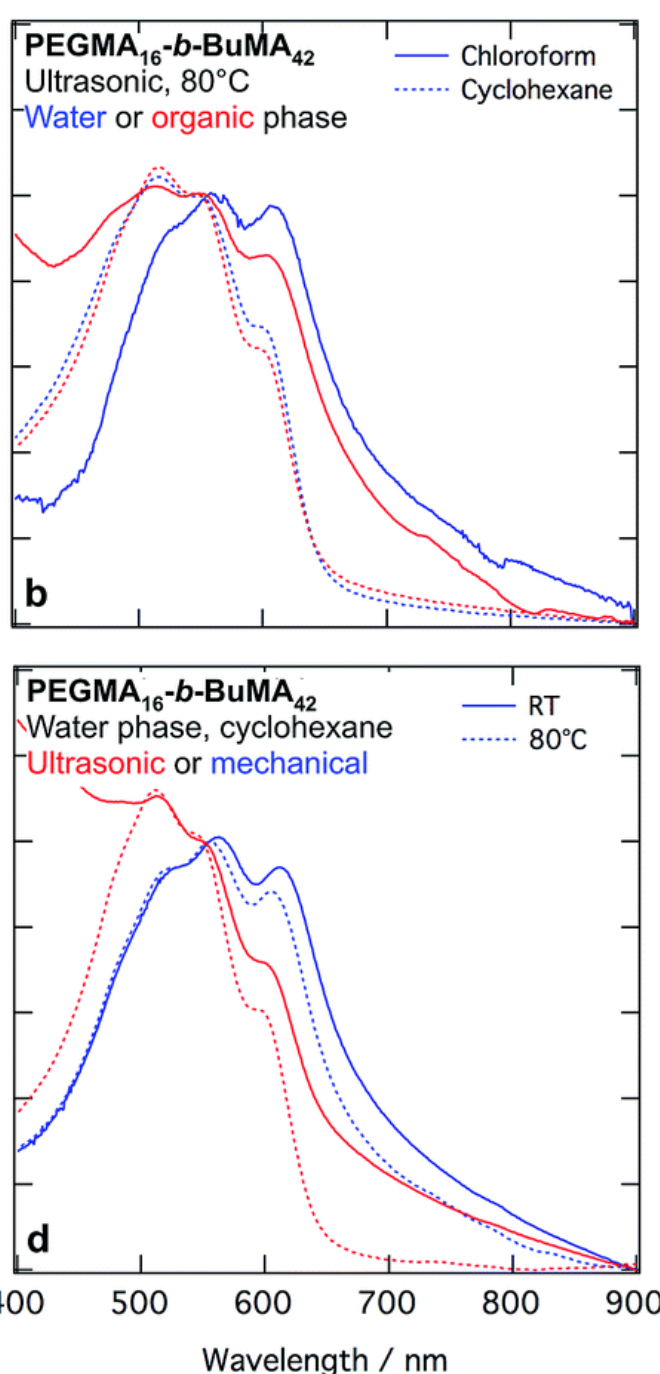

Fig. 3 UV-vis absorption spectra of P3HT dispersions made with (a) BuMA $_{59}$-b-DMAEMA ${ }_{83}$ and (b) PEGMA ${ }_{16}$-b-BuMA $A_{42}$, respectively, whereby the macrosurfactant was dissolved in the water- (blue) or oil phase (red), chloroform (solid line) or cyclohexane (dotted line) was used as the solvent for P3HT. UV-vis absorption spectra of P3HT dispersions made with (c) BuMA $_{59}$-b-DMAEMA $A_{83}$ and (d) PEGMA 16 -b-BuMA ${ }_{42}$, respectively. These emulsions were homogenised ultrasonically (red) or mechanically (blue) at RT (solid line) or $80^{\circ} \mathrm{C}$ (dotted line). Thereby, the macrosurfactant was dissolved in the water phase and cyclohexane was used to dissolve P3HT. 

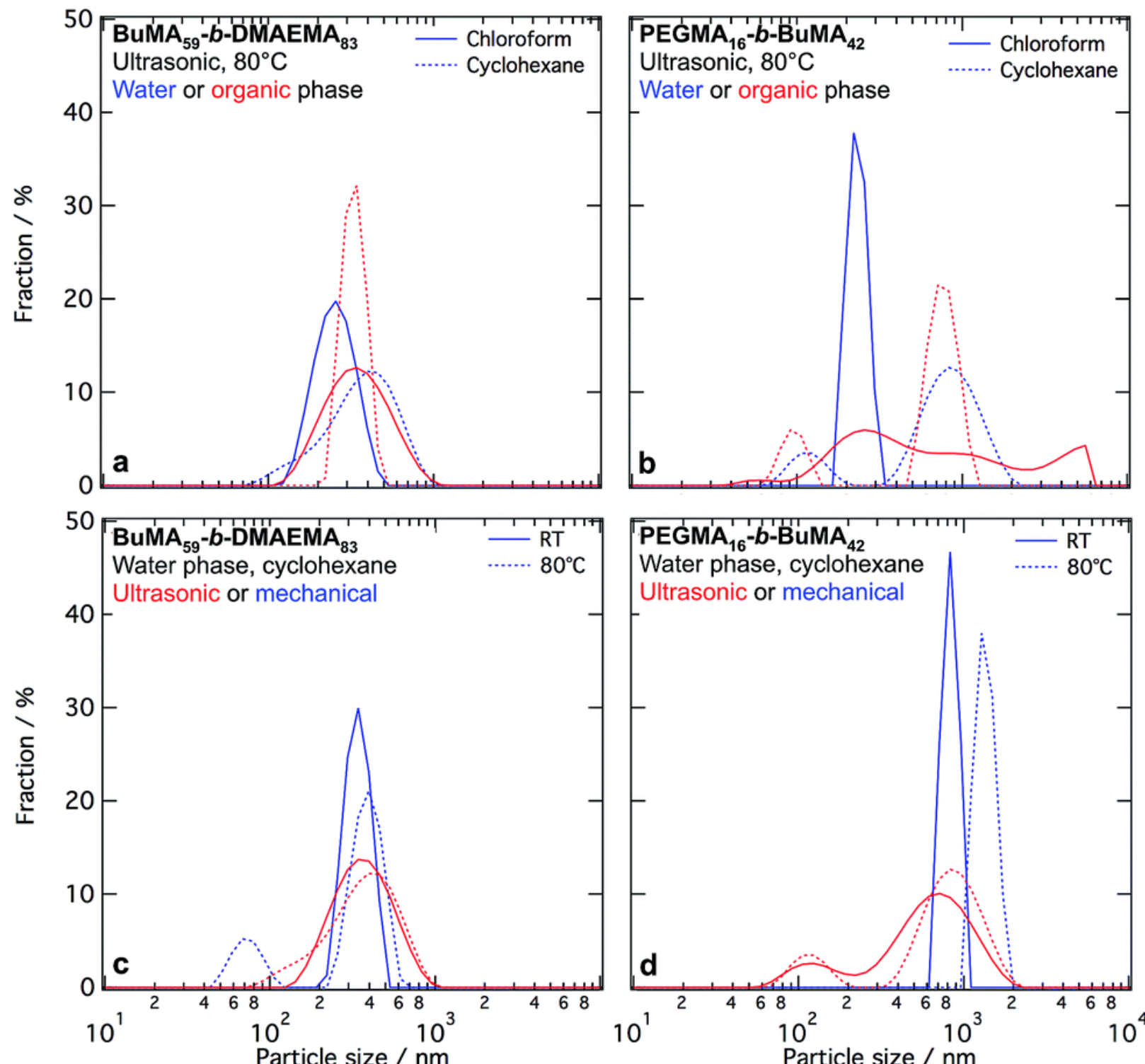

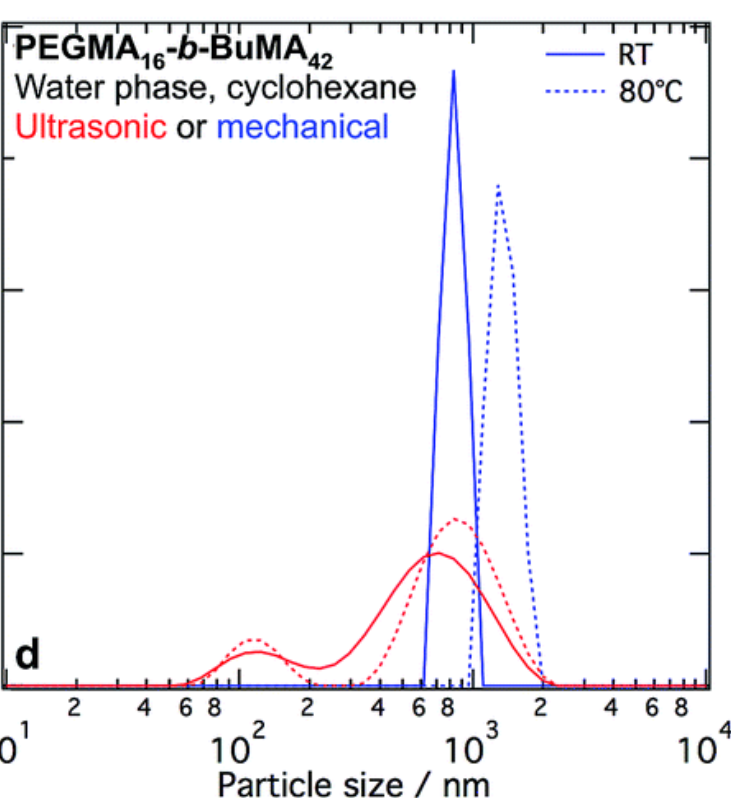

Fig. 4 Size distribution of P3HT particles in dispersions made with (a) BuMA $_{59}$-b-DMAEMA ${ }_{83}$ and (b) PEGMA ${ }_{16}$-b-BuMA ${ }_{42}$, respectively, where the macrosurfactant was dissolved in the water(blue) or oil phase (red) and chloroform (solid line) or cyclohexane (dotted line) was used to dissolve the P3HT. Size distribution of P3HT particles in dispersions made with (c) BuMA $A_{59}$-b-DMAEMA ${ }_{83}$ and (d) PEGMA 16 -b-BuMA ${ }_{42}$, respectively, whereby the emulsions were homogenised ultrasonically (red) or mechanically (blue) at RT (solid line) or 80 ${ }^{\circ} \mathrm{C}$ (dotted line), with the macrosurfactant being dissolved in the water phase and cyclohexane as solvent for P3HT. 


\section{Supplementary Information}

\section{Solubility behaviour of the polymeric macrosurfactant}

The behaviour of the macrosurfactant in a solvent provides an indication of how it would behave in the emulsion. Therefore we dissolved both macrosurfactants (which distinguish in the type of the hydrophilic block and block length) in water, cyclohexane and chloroform, the same solvents as we used in the emulsions. In an organic solvent, the block copolymers form in general inverse micelles with the hydrophobic block (BuMA) forming the shell (stretched chains) and the hydrophilic block (PEGMA or DMAEMA) coiled in the core. The theoretical value of the inverse PEGMA $_{16}-b-\mathrm{BuMA}_{42}$ micelles is $25.4 \mathrm{~nm}$, for $\mathrm{BuMA}_{59}-b$ DMAEMA $_{83} 46 \mathrm{~nm}$. In chloroform and cyclohexane, we found an average feature size close to the theoretical values of inverse micelles for both macrosurfactants (see Fig. S1), i.e. they form inverse micelles in these solvents. In addition, there appears a peak at a few $\mathrm{nm}$ when dissolved in chloroform. These are coiled single molecules (theoretically PEGMA $16-b$-BuMA $42: 2.84 \mathrm{~nm}, \mathrm{BuMA}_{59}-b$ DMAEMA $_{83}: 4.44 \mathrm{~nm}$ ) because all homopolymers of the block copolymers are well soluble in chloroform. The exception is PEGMA $_{16}-b$-BuMA 42 in chloroform where average size of the features is $100 \mathrm{~nm}$.

In water, micelles are formed in theory but the features we found are much larger than expected (see Fig. S1). For $\mathrm{BuMA}_{59^{-}} b-$ DMAEMA $_{83}$, the features are about the double of the theoretical value $(57 \mathrm{~nm})$. Most probably, micelles with not as collapsed chains in the core or small aggregates are formed. For PEGMA $16^{-} b-$ BuMA $_{42}$, even bigger aggregates are formed.

The theoretical value of the inverse PEGMA $_{16}-b-\mathrm{BuMA}_{42}$ micelles is $25.4 \mathrm{~nm}$, for $\mathrm{BuMA}_{59}-b$-DMAEMA ${ }_{83} 46 \mathrm{~nm}$. The theoretical value assumes that the polymer chains are fully extended and that the hydrophilic block is in the core of the micelle, while the hydrophobic block in the corona of the micelle (similar to Raduan et $\mathrm{al}^{25}$ ).
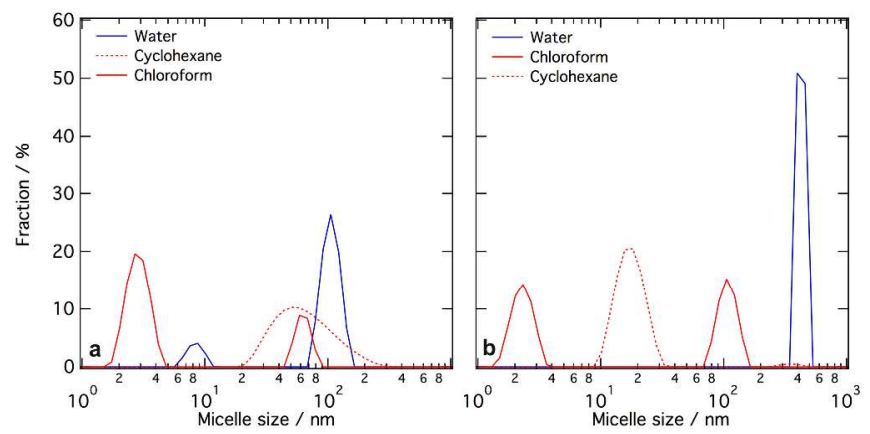

Fig. S1: Size distribution of a) $B u M A_{59}-b-D M A E M A_{83}$ and b) $P E G M A_{16}-b-$ $B u M A_{42}$ micelles, respectively, in water, chloroform or cyclohexane. 


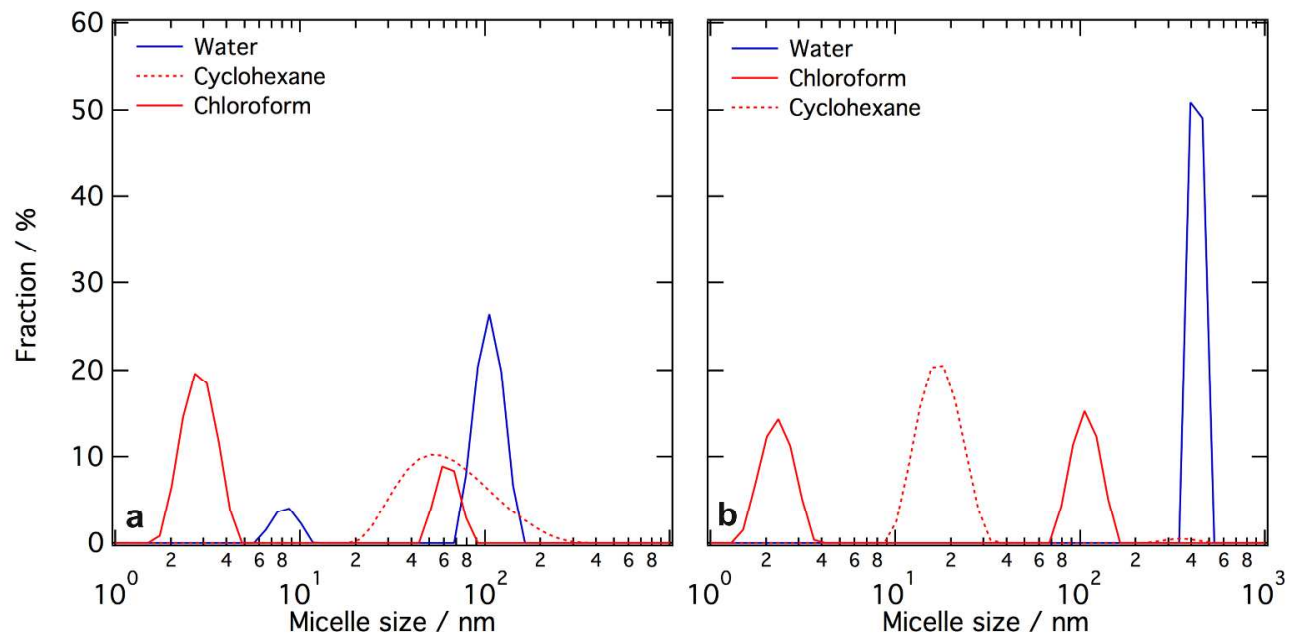

Size distribution of a) BuMA59-b-DMAEMA83 and b) PEGMA16-b-BuMA42 micelles, respectively, in water, chloroform or cyclohexane. 


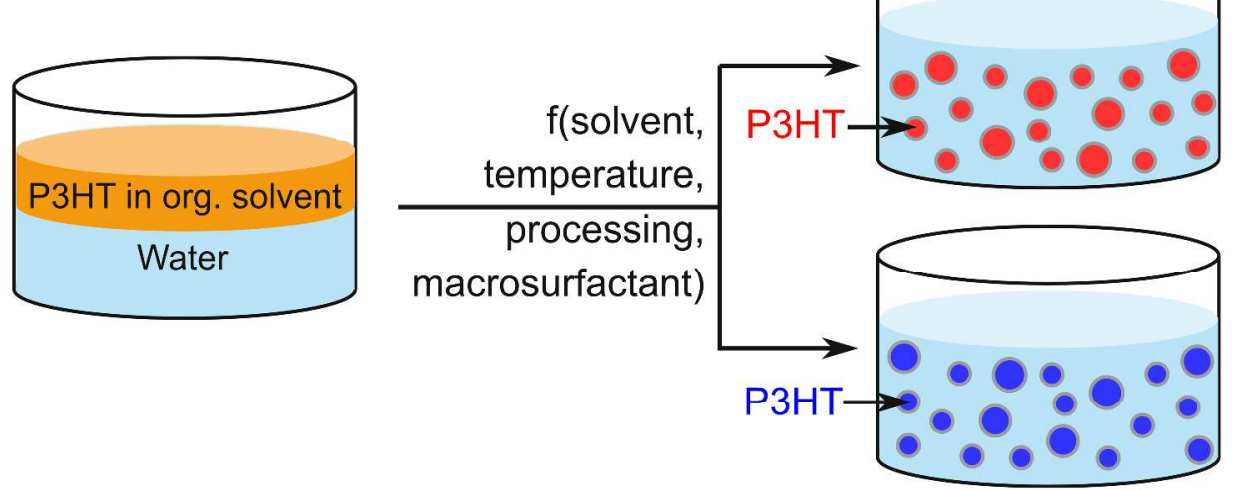

